\title{
ACTIVISMO FEMINISTA EN INSTAGRAM. EL CASO DE LA CAMPAÑA NACIONAL POR EL DERECHO AL ABORTO LEGAL SEGURO Y GRATUITO EN ARGENTINA
}

\author{
Dra. Marina Acosta \\ Instituto de Estudios de América Latina y el Caribe \\ Facultad de Ciencias Sociales-Universidad de Buenos Aires, \\ Buenos Aires, Argentina \\ macosta@sociales.uba.ar \\ ORCID ID: https://orcid.org/0000-0002-8270-4372
}

Recibido el 26 de julio de 2019

Aceptado el 26 de abril de 2020

\section{Resumen}

Durante 2018 la democracia argentina asistió al debate del aborto que hasta ese entonces había estado excluído de la agenda pública. La Campaña Nacional por el Derecho al Aborto Legal Seguro y Gratuito organizó, desde las plataformas digitales, la acción colectiva a favor de la interrupción voluntaria del embarazo. El objetivo general de la investigación es describir las estrategias que llevó adelante la Campaña, en Instagram, para propiciar el proceso de conversación digital en torno al aborto. La metodología utilizada es el clásico análisis de contenido combinado con el web scraping y diferentes open softwares. El estudio se enmarca en los desarrollos teóricos de la tecnopolítica y el ciberactivismo.

Palabras clave: feminismo, aborto, ciberactivismo, Argentina. 


\title{
FEMINIST ACTIVISM ON INSTAGRAM. THE CASE OF THE NATIONAL CAMPAIGN FOR THE RIGHT TO SAFE AND FREE LEGAL ABORTION IN ARGENTINA
}

\begin{abstract}
During 2018, Argentine democracy attended the abortion debate that until then had been excluded from the public agenda. The National Campaign for the Right to Legal, Safe and Free Abortion organized, on digital platforms, collective action in favor of voluntary termination of pregnancy. The main objective of this research is to describe the strategies carried out by the Campaign, on Instagram, to promote the process of digital conversation around abortion. The methodology uses the classic content analysis combined with web scrapping and various open software. The study is framed in the theoretical developments of technopolitics and cyberactivism.
\end{abstract}

Keywords: feminism, abortion, cyberactivism, Argentina. 


\section{INTRODUCCIÓN}

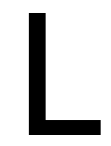

as nuevas tecnologías han cambiado las formas de comunicación social. El entorno digital ha posibilitado que las redes sociales se presenten como herramientas de comunicación alternativas para el activismo. Los movimientos sociales recurren al uso de las plataformas virtuales para que sus acciones logren más alcance y mayor visibilidad.

Durante 2018 la democracia argentina asistió al debate del aborto que hasta ese entonces había estado excluido de la agenda pública. La autocomunicación de masas se convirtió en la protagonista de esa discusión histórica en tanto propició un intenso momento de democracia deliberativa (Habermas, 1998; 2001). Las redes sociales se transformaron en los lugares privilegiados donde se desarrolló el intercambio discursivo.

De acuerdo a una encuesta realizada por Amnistía Internacional y el Centro de Estudios de Estado y Sociedad (CEDES), en marzo de 2018, la mayoría de la sociedad argentina (59\%) expresaba su apoyo a la despenalización y legalización del aborto ${ }^{1}$.

Desde sus redes sociales (Facebook, Twitter e Instagram), la Campaña Nacional por el Derecho al Aborto Legal, Seguro y Gratuito (en adelante la Campaña) organizó la acción tecnopolítica a favor de la interrupción voluntaria del embarazo en Argentina.

Un dato que no debe soslayarse es el novedoso protagonismo que tuvieron las alumnas de los colegios secundarios durante todo el proceso de discusión parlamentaria. La participación de esos sectores de la población en las audiencias públicas de la Cámara de Diputados y en las multitudinarias movilizaciones que se realizaron en Buenos Aires y en las principales ciudades del país fue destacable e inédita. El germen del activismo de las nuevas generaciones debe buscarse, sin dudas, en la irrupción del \#NiUnaMenos, en 2015, que activó una nueva agenda en las esferas públicas periféricas: las plataformas digitales (Acosta, 2018b; Sampedro y Resina, 2010). Incluso la novedad de este movimiento también estuvo dada porque fue capaz de activar un conjunto de frames para explicar la lucha de las mujeres para avanzar en la conquista de derechos (Acosta, 2019). Probablemente, la amplia tematización sobre la violencia de género que instalaron las marchas masivas del \#NiUnaMenos haya permitido que la demanda por el aborto legal hiciera mella en las jóvenes (Elizalde y Mateo, 2018).

1 Fuente: https://amnistia.org.ar/mas-de-la-mitad-de-la-sociedad-argentina-esta-a-favor-de-ladespenalizacion-del-aborto/. Consulta: julio de 2019. 
La interpelación a ese sector de la sociedad obligó al feminismo a apelar a otras formas de comunicación y servirse de las plataformas digitales para organizar la movilización social. Así, el objetivo general de la investigación es describir las estrategias que llevó adelante la Campaña, en la red social Instagram, para propiciar el proceso de conversación digital en torno al aborto. Son objetivos específicos: 1) identificar los tipos de publicaciones; 2) explicitar los modos de participación de los usuarios (engagement); 3) registrar la formación de las comunidades digitales.

La sociedad de la información y el conocimiento, entendida como nuevo paradigma comunicativo, permite mostrar cómo el uso de las tecnologías de la información y la comunicación (TIC) resulta una fértil herramienta de activación política ciudadana (Castells, 2009). Como la discusión que se dio en los microsistemas digitales se amplificó y se materializó en una acción colectiva, enmarcamos la movilización discursiva digital dentro de los desarrollos teóricos de la tecnopolítica pues ella da cuenta de la dimensión colectiva de la irrupción en la escena pública del movimiento feminista (Toret, 2015; 2013). Lo anterior nos permite afirmar que este tipo de movimientos consideran que las plataformas digitales ofrecen oportunidades para desarrollar sus repertorios de acción colectiva (Acosta y Demirdjian, 2016; Cammaerts, 2012).

El avance del feminismo y sus nuevas conquistas ha llevado a focalizar en las posibilidades que proporcionan las redes sociales para el activismo (Arias, 2017; Cook y Hasmath, 2014; Fotopoulou, 2014; Núñez, 2011; Núñez, Fernández y Peña, 2016; Núñez y Fernández, 2017; Sádaba y Barranquero, 2019). Las investgaciones se han centrado, principalmente, en Facebook y Twitter (Acosta, 2018a; Caro, 2015; Laudano, 2017; 2018; Navarro, Martínez y Vialás, 2018; Rosales, 2018; SánchezDuarte y Fernández-Romero, 2017; Turley y Fischer, 2018). En América Latina, son muy pocos los estudios de caso sobre el ciberactivismo feminista en Instagram (Azevedo, Jardim y Costa, 2017; Obregon y Klein, 2018), la red social que más ha crecido en los últimos años. En este sentido, creemos relevante aportar investigación empírica a ese incipiente campo de estudio.

\section{MARCO TEORICO}

La novedad y complejidad del fenómeno de la acción colectiva requiere, como advierte Manuel Castells, una innovación pluridisciplinar que permita seguir la dinámica de redes características de estos movimientos (2009; 2012). Esta idea postula dos cuestiones interrelacionadas: por un lado, el uso de las redes como herramientas de participación política y, por otro, que las TIC no son sólo un canal fundamental de expresión de los movimientos sociales sino además un componente relevante para comprender su configuración.

\subsection{Ciberactivismo y Tecnopolítica}


Los desarrollos de la plataforma conocida como Internet hicieron resurgir la idea del ensanchamiento del espacio público para la participación ciudadana (Goldberg, 2010; Norris, 2001; Sampedro, 2005). El espacio digital se presenta como una "nueva vía de participación" en la que la ciudadanía cobra un nuevo valor en términos de activismo y deliberación sobre los asuntos públicos. En esta línea, algunas visiones señalan que las redes sociales fomentan el compromiso cívico de los usuarios políticamente activos (De la Garza, Peña y Recuerdo, 2019; Mascheroni, 2017).

La web se transforma en una nueva esfera que ofrece una serie de recursos que favorecen la interconectividad y permiten a los actores sociales abrir vías de comunicación más inclusivas (Fernández, Corredor y Santín, 2011). Allí se pueden politizar demandas, agendar reclamos y viralizar información. Las oportunidades comunicativas que se derivan de la red favorecen la aparición de nuevas características en los cibermovimientos sociales (Ortiz, 2014; 2016).

Las tecnologías digitales de la autocomunicación de masas (Castells, 2009) proporcionan a la acción colectiva un poderoso motor que permite, por un lado, la difusión y persuasión de sus acciones y, por otro, la conformación de su identidad pública y colectiva (Diez y Laraña, 2017: 109). Las organizaciones, cuyo propósito es generar cambios de actitudes y comportamientos, conciben a las plataformas digitales como espacios de comunicación (Sádaba y Barranquero, 2019).

En el marco de la sociedad red, la ciudadanía se constituye también mediante las herramientas de debate, discusión y deliberación que ofrece la propia arquitectura de Internet. Los acontecimientos digitales que allí se producen conllevan una fuerte dimensión performativa; es decir, "crean con antelación en el digital el mundo que se quiere vivir en el mundo físico" (Toret, 2013: 51).

Tales desarrollos tienen como telón de fondo teórico a la tecnopolítica que "se basa en la comprensión masiva, intuitiva y profunda de la capacidad política de organizarnos en red mediados por la tecnología (...)" (Toret, 2015: 63). Se trata, en efecto, del uso estratégico de las herramientas digitales para la organización, comunicación y acción colectiva (Toret, 2013: 20). El concepto se relaciona con la idea de la autoorganización política en la sociedad red (Alcazan et al., 2012; Gutiérrez, 2014; Jurado, 2013).

El ejercicio de la autocomunicación de masas se suma a la larga lista de ejemplos que advierten, desde hace tiempo, un cambio en el paradigma de la comunicación. Desde el modelo clásico vertical del emisor-receptor se ha pasado a un sistema en el que múltiples actores se convierten en productores de mensajes que se amplifican por las redes de comunicación social en niveles globales y locales. Empero, no desconocemos que las plataformas digitales constituyen, también, manifestaciones de relaciones de poder entre productores institucionales y consumidores individuales (Castells, 2009; Dijck, 2016). 
El ecosistema de medios conectivos representa una infraestructura dinámica capaz de influir en la cultura (Dijck, 2016) y en la política (Castells, 2009; Ceron, Curini y lacus, 2013). De esta manera, los actores sociales interesados en visibilizar sus demandas deben desarrollar un sistema de comunicación eficaz basado en la difusión de información que vaya en dos direcciones: a los tomadores de decisión y a otros sectores sociales que puedan convertirse en aliados.

Por cierto, las plataformas digitales crean grupos de pertenencia. La participación de los usuarios y las interacciones que se generan con otros usuarios o con ciertos temas lleva a la formación de las comunidades virtuales. Definimos a éstas como un conjunto de usuarios y usuarias cuyos miembros interactúan entre sí; las une la transacción, el interés o las relaciones personales (Gupta y Kim, 2004).

Respecto de las temáticas sociales, en general, los clusters suelen configurarse con características del arquetipo grupos densos; en ellos se registra una alta interconexión de sujetos con muy pocos participantes aislados lo que deriva en una conversación densa (Smith et al., 2014: 3-5).

\section{MÉTODO}

Además de la revisión bibliográfica, esta investigación recurre al clásico análisis de contenido (AC). Se trata de una metodología destinada a formular, a partir de ciertos datos, inferencias reproducibles y válidas que puedan aplicarse a un contexto (Krippendorff, 1990: 28).

Como las redes sociales proporcionan una gran cantidad de información, que impide que los datos se analicen de forma manual, combinamos el AC con el web scraping para extraer y organizar información que no es posible obtener mediante métodos convencionales. El web scraping no sólo permite vencer las limitaciones del AC tradicional sino además conseguir mayores muestras y mejor codificación de datos.

La confiabilidad alcanzada a través de la tecnología disminuye los sesgos que puedan desviar la interpretación (Arcila-Calderón, Barbosa-Caro y CabezueloLorenzo, 2016). Nos adentramos en el ecosistema digital y utilizamos una combinación de open softwares para analizarlo. El proceso de análisis sigue la siguiente secuencia: a) captura de datos, b) análisis de datos y c) presentación de los resultados mediante gráficos.

a) Los datos fueron recolectados con Instagram Scraper en Python. La herramienta generó un archivo JSON que luego convertimos al formato ".xlsx". Para poder exportarlo a los softwares que identificamos en el siguiente punto decidimos pasarlo, a su vez, a un archivo ".csv". 
b) Para el análisis utilizamos dos softwares. En Rstudio importamos el archivo ".csv". y procedimos a la manipulación de los datos, utilizando un objeto de la clase dataframe que nos proporcionó los datos cuantitativos (porcentajes y promedios). Para acceder a ciertos aspectos técnicos de la red estudiada, desde Gephi importamos el mismo archivo ".csv". Este software nos permitió identificar las características (modularidad, cantidad de aristas y clusters) de los nodos construidos en las diferentes interacciones de los usuarios. Las relaciones entre nodos y aristas son esenciales para construir datos sobre la articulación, densidad, organicidad y conectividad de una determinada red (Ábrego, Bona y Reguillo, 2018). En el análisis, los usuarios centrales (nodos) se enlazan (aristas) con otros usuarios (nodos) y constituyen la subestructura de la expansión de la red estudiada (Giraldo-Luque, Fernández-García y Pérez-Arce, 2018). Las comunidades se generan cuando dos o más nodos interactúan entre sí con distintos grados y pesos.

c) Con Tableau graficamos la interacción de los usuarios y los tipos de publicación y con Gephi elaboramos el grafo (conjunto de nodos y aristas) de la conversación virtual.

\subsection{Instagram}

Como campo principal de análisis hemos elegido a Instagram dado que fue el espacio digital que construyó el relato icónico de la organización, discusión, difusión y movilización de la Campaña mientras duró el debate parlamentario del proyecto de ley en 2018.

Se trata de la red social con mayor crecimiento en los últimos años. Tiene más de 1.000 millones de usuarios activos mensuales en todo el mundo y el rango etario que más la usa es el comprendido entre los 18 y los 34 años. Después de Facebook (83\%), Instagram es la red más utilizada por los argentinos (49\%). Cuenta con un total de 16 millones de usuarios activos (mensuales): un 55\% de los perfiles declarados son mujeres y un $45 \%$ hombres (Hootsuite y We are Social, 2018).

Originariamente fue diseñada para ser utilizada desde los teléfonos celulares para subir fotografías. En otras palabras, la principal herramienta comunicativa de esta red social es la imagen (Carrasco, Villar y Martín, 2018). La aplicación les permite a los usuarios enviar mensajes a otros usuarios, grabar y subir vídeos de hasta 59 segundos, insertar varias imágenes en una misma publicación y compartirlas (de modo sencillo) en otras redes sociales.

Además de ser una red esencialmente visual es la que más engagement genera con sus contenidos. En términos generales, en la plataforma hay dos tipos de participación: reacciones (Me gusta) y comentarios. Estos tipos de engagement revelan la conducta más o menos participativa de los usuarios. Los comentarios representan el nivel más activo de la participación (Fernández, 2016). 
Un sondeo señala que el $76 \%$ de la muestra analizada se informa de las noticias a través de Facebook, mientras que un $49 \%$ lo hace por WhatsApp y un $26 \%$ por Instagram ${ }^{2}$. En cualquier caso, parece confirmarse el incremento en el uso de las redes sociales como canal de acceso a las noticias (Mitchell y Page, 2015).

\section{MUESTRA}

El análisis de contenido se aplicó a la cuenta que la Campaña tiene en Instagram (@CamAbortoLegal) con más de 212 mil seguidores (julio de 2019).

Las unidades de análisis fueron cada una de las publicaciones (imágenes y videos). Se han excluido del análisis las stories, por lo que no se han tenido en cuenta sus visualizaciones, mensajes directos recibidos ni acciones con stickers.

La muestra total se compone de 535 posteos recolectados entre el 1 de marzo al 9 de agosto de 2018. El recorte temporal abarca desde el momento en que el presidente Mauricio Macri anuncia, en la inauguración de las sesiones ordinarias del Congreso (1 de marzo), que habilitaría la discusión parlamentaria sobre la despenalización del aborto hasta el día que el Senado votó en contra de la sanción de la ley (9 de agosto).

Para describir la actividad de la cuenta se diseñó un instructivo de aplicación donde cada una de las unidades de análisis fue codificada con la siguiente ficha de análisis: fecha, tipo de publicación (imagen o video), contenido del mensaje, cantidad de comentarios, cantidad de reacciones, hashtag/s utilizado/s.

\section{RESULTADOS}

Durante el período estudiado, la Campaña posteó 535 publicaciones que tuvieron 8.420 comentarios y 1.924 .625 reacciones, con un promedio diario de 0.22 videos, 1.13 imágenes, 4910 reacciones y 21.47 comentarios. Todas las publicaciones fueron acompañadas por al menos un hashtag. En la Figura 1 se observan los tipos de publicaciones:

2 Fuente: http://meso.com.ar/wp-content/uploads/2018/11/12.-UdeSA-Especial-Medios.pdf. Consulta: julio de 2019. 
Fuente: Elaboración propia.

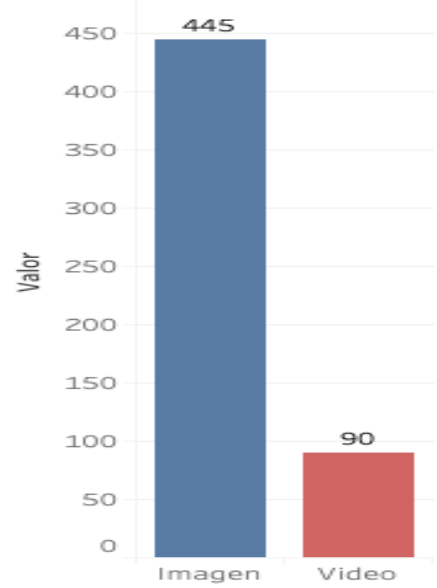

Figura 1. Publicaciones

La Campaña ha posteado más imágenes (83.17\%) que videos (16.82\%). El uso privilegiado de estos formatos en la red social Instagram responde no sólo al poder de viralización que tienen sino además a que los contenidos icónicos y audiovisuales generan una mayor atención e interacción de los usuarios.

Los meses donde se registraron la mayor cantidad de publicaciones fueron abril (147 posteos) y agosto (110 posteos). Durante abril- en las comisiones de Legislación General, Legislación Penal; Familia, Mujer, Niñez y Adolescencia y Acción Social y Salud Pública de la Cámara de Diputados- tuvieron lugar las audiencias públicas en las que más de setencientos expositores de diversos ámbitos argumentaron a favor y en contra de la despenalización del aborto. Durante agosto, la Cámara de Senadores discutió y rechazó el proyecto.

Las tres posteos que generaron más reacciones coinciden con el mes de agosto: 1) el video del discurso de la senadora por la provincia de Corrientes, Ana Claudia Almirón, durante la cesión del 8 de agosto reconociendo la lucha de las mujeres por el aborto (59.659 reacciones, 08/08/18); 2) una imagen de cientos de mujeres y sus pañuelos verdes alzados, durante la vigilia de la votación en la Cámara alta, que se publicó tras frustrarse la sanción de la ley con el hashtag \#VaASerLey (43.466 reacciones, 09/08/18); 3) la placa verde ${ }^{3}$ anunciando el conteo con la inscripción "El Senado vota el aborto legal en Argentina" (28.732 reacciones, 08/08/18).

3 Con la placa verde, la Campaña imitó la estrategia del canal de noticias Crónica TV que cuenta los días que restan para llegar a la primavera, estación favorita de la señal. Las placas verdes mostraron, en diferentes momentos, los días que faltaban para la votación del proyecto en Diputados y Senadores. 
Las publicaciones con más comentarios fueron ${ }^{4}$ : 1) un video de un militante "provida" tachando con aerosol un pañuelo verde pintado por las activistas frente a la Catedral de la ciudad de La Plata (554 comentarios, 28/06/18); 2) un video resumiendo la movilización del 13J con el texto "Todxs en un mismo grito \#AbortoLegalYA" (441 comentarios, 14/06/18); 3) una imagen con la leyenda "Desde la Campaña Nacional por el Derecho al Aborto Legal, Seguro y Gratuito difundimos el mapa de la ubicación de una movilización histórica" (231 comentarios, 06/08/18).

\subsection{Interacciones}

Los meses de mayor interacción (reacciones + comentarios) coinciden con el tratamiento del proyecto tanto en la Cámara de Diputados (junio) con en la de Senadores (agosto), tal como puede verse en el siguiente gráfico:

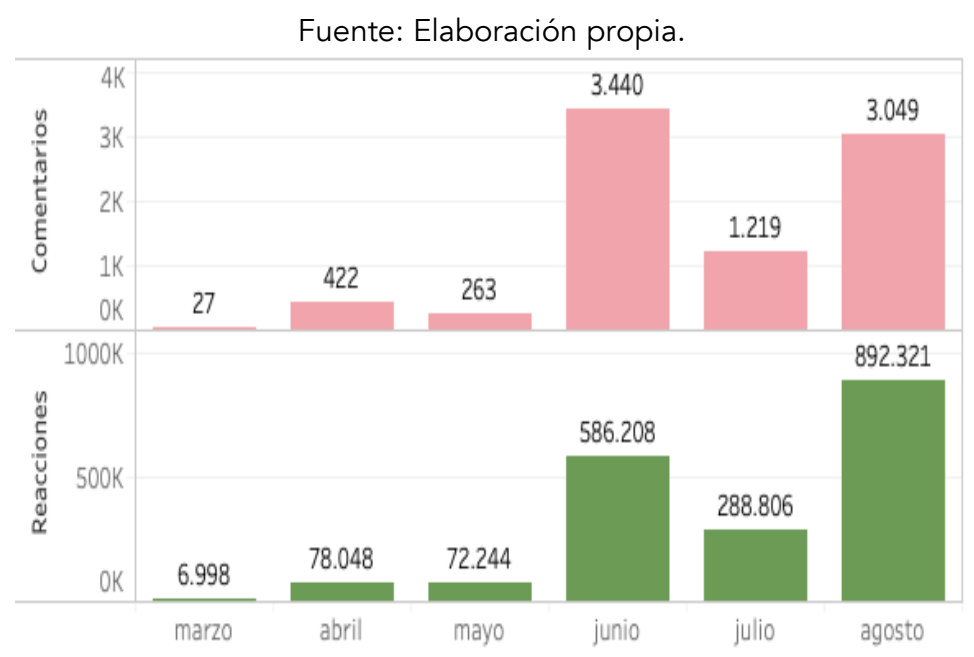

Figura 2. Interacciones

Los usuarios se mantuvieron muy interesados y participativos con los posteos en los meses finales de la discusión. De las interacciones totales $(n=1.933 .045)$, las reacciones fueron las que más engagement generaron (99.56\%); no hay que olvidar, sin embargo, que se trata del nivel menos activo de participación. Los comentarios fueron muy escasos $(0.43 \%)$ pero se incrementaron en junio y agosto con el tratamiento de proyecto en el Congreso.

Conforme pasaron los días entre el debate en la Cámara baja y la Cámara alta la actividad experimentó una meseta, como se advierte en la Figura 2, por lo que los días más intensos del activismo on line estuvieron centrados en mantener la visibilidad del proyecto, especialmente durante su votación.

4 Aunque se han contado los comentarios de los usuarios para analizar las interacciones, sus contenidos no han sido tenidos en cuenta para el análisis. 
Respecto del tratamiento parlamentario, la Campaña se mantuvo atenta a acontecimientos importantes y eso se explicita en la actividad de su cuenta: 1) la celebración por el dictamen de mayoría (junio); 2) el inicio del debate en el Senado (junio); 3) la negociación de los senadores "verdes" con los "provida" que solicitaban cambios en el proyecto (julio); 4) el posicionamiento frente a las movilizaciones de grupos católicos y evangelistas contrarios a la sanción de la ley (julio-agosto); 5) las movilizaciones y convocatorias para participar en el espacio público ante el posible rechazo a la norma (agosto).

La actividad de la Campaña centrada en los últimos tres puntos no ha sido aleatoria. Si ha mantenido un interés en ellos ha sido porque pudo percibir la ola de iniciativas regresivas en la agenda de los derechos de las mujeres en Argentina. La alianza entre la Iglesia católica y la evangelista -unidas en la consigna "salvemos las dos vidas"- adquiría una fuerza que hasta la discusión parlamentaria no se había manifestado con tanta intensidad en el país.

\subsection{Conversación}

La Figura 3 muestra una red densa de comunicación con fuertes vínculos. El software Gephi detectó un total de 578 nodos y 931 aristas. Luego de aplicar una combinación de algoritmos de distribución (layaout)- YiFan Hu y Force Atlasllegamos al siguiente grafo:

Fuente: Elaboración propia en base a los datos analizados por Gephi

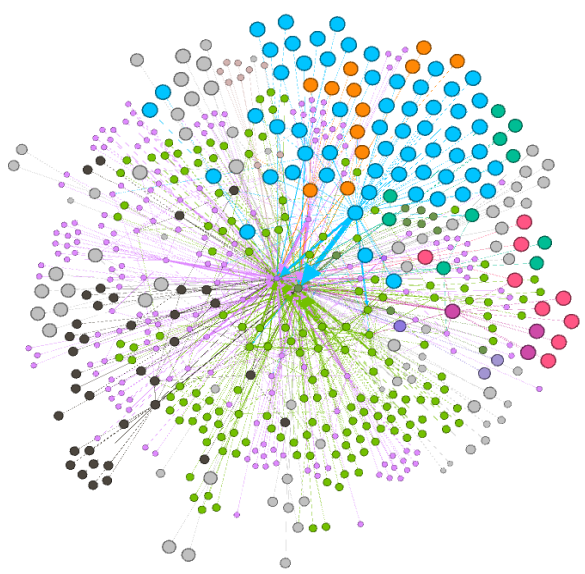

Figura 3. Grafo de la conversación

Los colores de los nodos representan las comunidades digitales. En el grafo vemos la preeminencia de tres colores que se corresponden con los clusters de mayor modularidad: violeta (32.35\%), verde $(29.41 \%)$ y celeste $(10.21 \%)$. El grado de modularidad total de la red es bajo (0.29). Las conexiones intramodulares son sólidas al igual que las conexiones con nodos de otros módulos. Esto evidencia una 
alta interacción entre las comunidades, por lo que la forma que han tomado corresponde al arquetipo de grupos densos en los que se observa una alta interconexión de nodos con muy pocos participantes aislados. Consecuentemente, se genera una conversación densa.

Los temas alrededor de los cuales se han agrupado los clusters son, en orden de colores: [violeta] la vigilia en las calles mientras el proyecto se discutía en Senadores; [verde] la discusión en la Cámara alta; [celeste] la discusión en la Cámara baja. Las comunidades se han configurado alrededor de esos temas y allí ha tenido lugar la conversación virtual.

Valga también aquí hacer referencia a los posteos que vincularon la actividad de Instagram con la de Twitter, la otra red social protagonista del proceso de discusión. Los tres hashtags más recurrentes fueron \#AbortoLegalYa (27\%), \#YoVotoAbortoLegal (26\%) y \#Pañuelazo (15\%). El uso de este último hashtag remite al pañuelo verde que identifica a la Campaña y que se transformó en una forma de manifestación y expresión de apoyo a la despenalización del aborto.

La Campaña ha utilizado los hashtags con tres objetivos: permitir que una misma información circule por distintos lugares, conectar a usuarios con otros de otras redes y potenciar el alcance de las publicaciones. Esto explica el objetivo del equipo de comunicación digital de mantener sincronizada las cuentas de sus redes sociales para que todas funcionasen en espejo y así reforzar los mensajes.

\section{CONCLUSIONES}

La metodología utilizada nos ha permitido cumplir con los objetivos de esta investigación. En función de lo expuesto podemos realizar una serie de consideraciones a modo de conclusiones preliminares.

Hemos dado cuenta, en primer lugar, que la Campaña recurrió más a publicaciones de imágenes que de videos y que lo hizo durante los meses en los que el proyecto de ley se debatió en el Congreso. En segundo lugar, hemos advertido si bien las reacciones fueron las que más engagement generaron representan el nivel menos activo de participación. En tercer lugar, observamos que la actividad de los usuarios se incrementó especialmente en los momentos de la discusión parlamentaria y que se registraron conexiones sólidas entre las comunidades de usuarios que produjo una conversación densa entre ellas.

Para la Campaña, Instagram se constituyó como un canal comunicativo a través del cual pudo mantener una relación directa con sus seguidores. El uso particular que hizo de esta plataforma permite afirmar, por un lado, que las experiencias de socialización estuvieron mediadas por el intercambio de imágenes y videos y, por consiguiente, que el poder de lo visual ha sido determinante en la construcción de las identidades (Svensson y Russmann, 2017). 
Guiadas por fines de incidencia políticosocial, las activistas utilizaron esta red para organizar y coordinar acciones y compartir información. Como lo hicieron con el resto de sus cuentas en otras redes sociales, se sirvieron de Instagram para visbilizar sus reclamos. Al mismo tiempo, desde allí alentaron el involucramiento y participacion activa de la ciudadania en la discusión de la despenalización y legalización del aborto. De este modo abrieron la posibilidad de vincular esa demanda con otras reivindicaciones; por caso, la violencia de género del \#NiUnaMenos, la igualdad de derechos en las marchas del \#8M y el acompasamiento con el movimiento feminista que se viene manifestando a escala mundial.

La frustrada sanción de la ley no debe considerarse como un fracaso de la Campaña. La lucha por el derecho al aborto legal, seguro y gratuito se extendió más allá de las fronteras domésticas y se replicó en otros países de la región. La movilización social que espoleó no tuvo precedentes. Es así que podemos concebir a este movimiento como un ejemplo exitoso de campaña tecnopolítica (Toret, 2013; 2015). Se trató de una construcción colectiva a través de los microsistemas digitales que posibilitaron una dinámica de participación que se fue gestando con flujos de información masivo que, a su vez, le permitió desafiar no sólo las estructuras sociales tradicionales sino también a los poderes políticos.

El reclamo por la legalización del aborto ha sido central en la agenda del movimiento feminista. Con sus estrategias comunicativas, desplegadas en el espacio público tradicional y las esferas públicas periféricas (Sampedro y Resina, 2010), la Campaña se ha convertido en guía de buena parte de la opinión pública.

Con todo, a pesar de los avances en el reconocimiento y ampliación de derechos, la situación particular de los derechos reproductivos sigue siendo una deuda pendiente del Estado argentino. 


\section{Referencias bibliográficas}

ÁBREGO, V. H., BONA, Y. y REGUILLO, R. (2018): Inteligencia artificial electoral. Tercer \#DebateINe a la Presidencia. En El efecto AMLO. Guadalajara: ITESO.

ACOSTA M. y DEMIRDJIAN, S. (2016): Los medios y la política. Estructuras de oportunidad para la acción colectiva. Avatares. Comunicación y Cultura, No. 11. Disponible en: http://ppct.caicyt.gov.ar/index.php/avatares/article/view/8633/pdf

ACOSTA, M. (2018a): Ciberactivismo feminista. La lucha de las mujeres por la despenalización del aborto en Argentina. Sphera Publica, 2 (18), pp. 2-20.

(2018b): Violencia de género y tecnopolítica. La génesis del \#NiUnaMenos en Argentina. En: Salazar, R. y Zebadúa (Eds.): Las formas de violencia en América Latina contemporánea. Buenos Aires: El Aleph.com, pp. 113-137.

(2019): Enredadas. Estrategias comunicacionales del feminismo. Revista Mestiza. Disponible en: https://revistamestiza.unaj.edu.ar/enredadas/

ALCAZAN, ARNAUMONTY, AXEBRA, QUODLIBETAT, LEVI, S., SUNOTISSIMA, TAKE THE SQUARE y TORET (2012): Tecnopolítica, Internet y R-evoluciones. Barcelona: Icaria.

ARCILA-CALDERÓN, C., BARBOSA-CARO, E. y CABEZUELO-LORENZO, F. (2016): Técnicas Big Data: análisis de textos a gran escala para la investigación científica y periodística. El profesional de la información, 25 (4), pp. 623-631.

ARIAS, A. (2017): La cimentación social del concepto mujer en la red social Facebook. Revista de Investigación Educativa, 35 (1), pp. 181-195.

AZEVEDO, A., JARDIM, M. y COSTA, A. (2017): Empoderamento feminino en Belém: Análise das narrativas publicadas no perfil do Instagram @Girlpowerbelem. Asas da Palavras, 14 (1), pp. 71-82.

CAMMAERTS, B. (2012). Protest logics and the mediation opportunity structure. European Journal Communication 27 (2), pp. 117-134.

CARO, L. (2015): Construir y comunicar un "nosotras" feminista desde los medios sociales. Una reflexión acerca del "feminismo del hashtag". Commons, 4 (2), pp. 124-154. Disponible en: https://revistas.uca.es/index.php/cayp/article/view/3098. [Consultado: junio de 2019].

CARRASCO, R., VILLAR, E. y MARTíN, M. A. (2018): Artivismo y ONG: Relación entre imagen y «engagement» en Instagram. Comunicar, 26 (57), pp. 29-38. 
CASTELLS, M. (2009): Comunicación y poder. Madrid: Alianza.

(2012): Redes de indignación y esperanza. Madrid: Alianza.

CERON, A, CURINI, L. y IACUS, S. (2013): Every tweet counts? How sentiment analysis of social media can improve our knowledge of citizens' political preferences with an application to Italy and France. New Media \& Society, 15 (8), pp. 1-20. DOI: http://doi.org/10.1177/1461444813480466

COOK, J. y HASMATH, R. (2014): The discursive construction and performance of gendered identity on social media. Current Sociology, 62 (7), pp. 975-993. DOI: https://doi.org/10.1177/0011392114550008

DE LA GARZA, D., PEÑA, J. y RECUERDO, F. (2019): La participación política online de los jóvenes en México, España y Chile. Comunicar, No. 61. DOI: https://doi.org/10.3916/C61-2019-07

DIEZ, R. y LARAÑA, E. (2017): Democracia, dignidad y movimientos sociales. El surgimiento de la cultura cívica y la irrupción de los indignados en la vida pública. Colección Monografías, No. 308. Madrid: CIS.

DIJCK, J. (2016): La cultura de la conectividad. Una historia crítica de las redes sociales. Buenos Aires: Siglo XXI.

ELIZALDE, S. y MATEO, N. (2018): Las jóvenes: entre la "marea verde" y la decisión de abortar. Salud Colectiva, 14 (3), pp. 433-446. DOI: 10.18294/sc.2018.2026

FERNÁNDEZ, D., CORREDOR, P. y SANTíN, M. (2011): Nuevos espacios de comunicación, relación y activismo en la era digital: la Red como oportunidad para el feminismo. Asparkía, No. 22, pp. 61-72.

FERNÁNDEZ, E. (2016): Juegos Olímpicos, televisión y redes sociales. Barcelona: UOC.

FOTOPOULOU, A. (2014): Digital and networked by default? Women's organisations and the social imaginary of networked feminism. New Media and Society, 18 (6), pp. 1-17. DOI: https://doi.org/10.1177/1461444814552264

GIRALDO-LUQUE， S., FERNÁNDEZ-GARCÍA, N. y PÉREZ-ARCE， J. C. (2018): La centralidad temática de la movilización \#NiUnaMenos en Twitter. El profesional de la información, 27 (1), pp. 96-105.

GOLDBERG, G. (2010): Rethinking the public/virtual sphere: The problem with participation. New Media \& Society, 13 (5), pp. 739-754. DOI: https://doi.org/10.1177/1461444810379862 
GUPTA, S. y KIM, H. W. (2004): Virtual community: Concepts, implications, and future research directions. En Proceedings of the Tenth Americas Conference on Information Systems, NewYork, August 2004, pp. 2679-2687. Disponible en: https://aisel.aisnet.org/cgi/viewcontent.cgi?article=1896\&context=amcis2004

GUTIÉRREZ, A. (2014): Tecnopolitica. El uso y la concepción de las nuevas herramientas tecnológicas para la comunicación, la organización y la acción política colectiva. Disponible en:

http://www.gutierrezrubi.es/wpcontent/uploads/2014/11/Tecnopol\%C3\%ADtica.p df. [Consultado: mayo de 2019].

HABERMAS, J. (1998): Facticidad y Validez. Sobre el derecho y el Estado democrático de derecho en términos de teoría del discurso. Madrid: Trotta.

(2001): Teoría de la acción comunicativa. Madrid: Taurus.

HOOTSUITE y WE ARE SOCIAL (2018). Digital in 2018 in Southern America. Essencials insides into Internet, social media, mobile and ecommerce use across de region. Disponible en:

http://seer.unipampa.edu.br/index.php/siepe/article/view/40325/25139.

[Consultado: junio de 2019].

JURADO, F. (2013): Tecnopolítica, redes y movimientos sociales. De la revolución en las comunicaciones al cambio de paradigma. Sevilla: Universidad Pablo de Olavide.

KRIPPENDORFF, K. (1990): Metodología de análisis de contenido. Teoría y práctica. Barcelona: Paidós.

LAUDANO, C. (2017): Movilizaciones \#NiUnaMenos y \#VivasNosQueremos en Argentina. Entre el activismo digital y el \#FeminismoLoHizo. Seminário Internacional Fazendo Gênero 11 \& 13th Women's Worlds Congress (Anais Eletrônicos), Florianópolis. Disponible en:

http://www.wwc2017.eventos.dype.com.br/resources/anais/1503871106_ARQUIV O_Laudano_Texto_completo_MM_FG.pdf. [Consultado: junio de 2019].

(2018): El grito que tiño las redes. Revista Bordes. Disponible en:

http://revistabordes.com.ar/el-grito-que-tino-las-redes/. [Consultado: junio de 2019].

MASCHERONI, G. (2017): A practice-based approach to online participation: Young people's participatory habitus as a source of diverse online engagement. International Journal of Communication, Vol. 11, pp. 4630-4651. 
MITCHELL, A. y PAGE, D. (2015): The Evolving Role of News on Twitter and Facebook, Pew Research Center. Disponible en:

https://www.journalism.org/2015/07/14/the-evolving-role-of-news-on-twitter-andfacebook/. [Consultado: junio de 2019].

NAVARRO, C., MARTÍNEZ, L. y VIALÁS, S. (2018): Usos y valoración de Facebook como herramienta para la lucha contra la violencia de género en México. Teknokultura, 15 (2), pp. 285-299.

NORRIS, P. (2001): Digital divice. Civic engagement, information, poverty and the Internet Worldwide. Cambridge: Cambridge University Press.

NÚÑEZ, S. (2011): Activismo y colectivos en red praxis feminista "online" y violencia de género. Asparkía. Investigación feminista, No. 22, pp. 85-98.

NÚÑEZ, S. y FERNÁNDEZ, D. (2017): Narrativas transformadoras y testimonio ético: las estrategias discursivas de la Plataforma Feminista $7 \mathrm{~N}$, Contra las Violencias Machistas. index.comunicación, 7 (3), pp. 269-281. Disponible en:

http://journals.sfu.ca/indexcomunicacion/index.php/indexcomunicacion/article/vie w/31. [Consultado: junio de 2019].

NÚÑEZ, S., FERNÁNDEZ, D. y PEÑA, P. (2016): Ciberactivismo contra la violencia de género: fetichismo tecnológico e interactividad. Feminismo/s, No. 27, pp. 177195.

OBREGON, B. y KLEIN, E. (2018): As estratégias de engajamento de perfis feministas no Instagram. Anais do Salao Internacional de Ensino, pesquisa e extensao. Disponible en:

http://seer.unipampa.edu.br/index.php/siepe/article/view/40325/25139. [Consultado: junio de 2019].

ORTIZ, R. (2014): Los cibermovimientos sociales. Nuevas oportunidades comunicativas en la era de Internet y de la Web social, nuevas posibilidades de transformación democrática. Unpublished doctoral thesis. Universidad de Navarra.

(2016): Los cibermovimientos sociales: una revisión del concepto y marco teórico. Communication \& Society, 29 (4), pp. 165-183.

ROSALES, M. B. (2018): Ciberactivismo: praxis feminista y visibilidad política en \#NiUnaMenos. Pléyade, No. 22, pp. 63-85.

SÁDABA, I. y BARRANQUERO, A. (2019): Las redes sociales del ciberfeminismo en España: identidad y repertorios de acción. Athenea Digital, 19 (1), e2058. DOI: https://doi.org/10.5565/rev/athenea.2058 
SAMPEDRO, V. (Ed.) (2005): 13-M: Multitudes on line. Madrid: Los Libros de la Catarata.

SAMPEDRO, V. y RESINA, J. (2010). Opinión pública y democracia deliberativa en la Sociedad Red. Revista Ayer, No. 80, pp. 139-162.

SÁNCHEZ-DUARTE, J. M. y FERNÁNDEZ-ROMERO, D. (2017): Subactivismo feminista y repertorios de acción colectiva: Prácticas ciberfeministas en Twitter. El profesional de la información, 26 (5), pp. 894-902.

SMITH, M. A., RAINIE, L., SHNEIDERMAN, B. y HIMELBOIM, I. (2014): Mapping Twitter topic networks: From polarized crowds to community clusters. Pew Research Center, 20, 1-56. Disponible en:

https://www.pewinternet.org/2014/02/20/mapping-twitter-topic-networks-frompolarized-crowds-to-community-clusters/. [Consultado: junio de 2019].

SVENSSON, J. y RUSSMANN, U. (2017): Introduction to visual communication in the age of social media: Conceptual, theoretical and methodological challenges. Media and Communication, 5 (4), pp. 1-5. DOI:

http://dx.doi.org/10.17645/mac.v5i4.1263

TORET, J. (2013): Tecnopolítica: la potencia de las multitudes conectadas. El sistema red 15M, un nuevo paradigma de la política distribuida. Barcelona: UOC.

(Coord.) (2015): Tecnopolítica y 15M. La potencia de las multitudes conectadas. Un studio sobre la gestación y explosion del 15M. Barcelona: UOC.

TURLEY, E. y FISCHER, J. (2018): Tweeting back while shouting back: Social media and feminist activism. Feminism \& Psychology, 28 (1), pp. 128-132. 